\title{
Persistence of seeds, seedlings and plants, performance of transgenic wheat in weed communities in the field and effects on fallow weed diversity
}

\author{
Olena Kalinina ${ }^{\text {a,b,*, Simon L. Zeller }}{ }^{\mathrm{a}}$, Bernhard Schmid ${ }^{\mathrm{a}}$ \\ ${ }^{a}$ Institute of Evolutionary Biology and Environmental Studies, University of Zurich, \\ Winterthurerstrasse 190, 8057 Zurich, Switzerland \\ ${ }^{\mathrm{b}}$ Institute of Crop Science, University of Hohenheim, 70599 Stuttgart, Germany \\ *Corresponding author's present address: Institute of Crop Science (340b), University of \\ Hohenheim, Schloss, Westhof West, 115, DE-70599 Stuttgart, Germany. Tel. +4971145922372 \\ Email: olena.kalinina@uni-hohenheim.de
}

\begin{abstract}
Introduction of transgenic crops to agriculture has raised concerns about their effects on agroecosystems. We compared nine conventional lines of spring wheat with six genetically modified (GM) lines that contained transgenes of resistance against powdery mildew (Pm3b gene) or against fungi in general (Chi and Glu genes). We assessed the persistence and performance of these lines without competition and in experimental weed communities in the field, their seed germination in the laboratory, their survival in fallow plots and effects on post-harvest vegetation in the field.

In competition with weeds, the GM lines showed reduced seed number, plant height and biomass allocation to seeds than their corresponding non-GM lines. No such performance differences were observed without competition. The seedlings of GM lines did not persist longer than those of the corresponding non-GM lines in fallow plots. In the field, GM and non-GM wheat lines had similar performance and persistence and both were able to reproduce in dense weed communities and to survive during winter on fallow plots. Stored in soil in the laboratory, the seeds of GM and non-GM lines either germinated quickly or lost their viability after 3 months. GM and non-GM lines had no differential effects on the structure and diversity of fallow plant communities within the 6-month period of monitoring. Poor seed longevity yet successful plant persistence in weed communities or on fallow plots indicate that not removing a population of growing plants presents a greater risk than allowing the build-up of a soil seed bank regarding the potential escape of transgenic wheat to the environment. Strong varietal differences in persistence point out the importance of case-by-case assessment of new GM varieties and indicate that transgenic traits should preferably be introduced into varieties with low persistence.
\end{abstract}

\section{KEY WORDS}

Competition; persistence; powdery mildew; risk assessment; seed longevity; transgenic wheat.

\section{Introduction}

Introduction of transgenic crops to agriculture has raised concerns about their effects on agroand natural ecosystems. New introduced traits, in particular those conferring resistance to pathogens or abiotic stresses, have a potential to increase weediness or invasiveness of the genetically modified (GM) plants or their offspring leading to the persistence and spread of transgenes within agricultural, uncultivated, or natural areas (Andow and Zwahlen, 2006; Gilbert, 2013; Hails, 2000; Linder and Schmitt, 1994; Purrington and Bergelson, 1995; Quist and 
Chapela, 2001; Schmitt and Linder, 1994; Snow, 2002). Multiple studies reported unintended contamination of non-GM seed lots due to seed persistence in soil and GM plant volunteering in subsequent conventional crops or along the transport routes (Andersen et al., 2010; Demeke et al., 2006; Friesen et al., 2003; Heckt et al., 2014; Knispel and McLachlan, 2010; Mallory-Smith and Zapiola, 2008; Schafer et al., 2011). Volunteering and outcrossing of transgenic plants with traditional landraces or wild relatives pose a serious agricultural and environmental problem (Joergensen et al., 2009; Holman et al., 2011; Mercer and Wainwright, 2008; Mortensen et al., 2012; Piñeyro-Nelson et al., 2009). In particular, persistence and spread of the transgenes in agroecosystems and changes in weed management practices due to the introduction of herbicideresistant crops are known to have direct and indirect effects on biodiversity in fallow fields, often leading to the shifts in the species composition of the weed communities, with resistant genotypes dominating (Culpepper, 2006; Green and Owen, 2011; Harker et al., 2005b; Vencill et al., 2012; Warwick et al., 2009).

A thorough environmental risk assessment must therefore precede any release of the new transgenic plants to the environment. Such an assessment has to be done on a case-by-case basis and should include evaluation of the direct and indirect risks to the environment which the deliberate release of a new genetically modified organism may pose (EC, 2001; EFSA, 2011). For transgenic crops, their potential to persist and spread in agricultural and wild habitats through gene flow, persistence in the soil seed bank or as volunteers in subsequent conventional crops and outside agricultural fields, as well as the effects on the non-target organisms are among the major ecological risks to be addressed.

Wheat is the most important food crop in temperate climate with 723 million tons world production forecast for 2015 (FAO, 2015). To date, a range of traits has been introduced into wheat plants by the means of biotechnology, including tolerance to abiotic stresses (Bahieldin et al., 2005; Sivamani et al., 2000a; Xue et al., 2004), insect (Altpeter et al., 1999; Stoger et al., 1999) and disease resistance (Altpeter et al., 1999; Bieri et al., 2003; Brunner et al., 2011; Sivamani et al., 2000b; Wang et al., 2014b) and grain quality traits (Vasil et al., 2001). Most of the introduced traits can potentially provide fitness advantages to transgenic plants over their conventional relatives, e.g., through increased plant growth and vigor, fecundity or improved survival under abiotic or biotic stresses (Sivamani et al., 2000a; Snow et al., 2003; Wang et al., 2014a; Xue et al., 2004).

We used nine non-GM and six GM lines or varieties (later simply called lines) of spring wheat (Triticum aestivum L.) to study the persistence of plants of these lines in the environment at different stages of their life cycle. The GM lines were genetically modified to be resistant against powdery mildew (Blumeria graminis f.sp. tritici (DC.) Speer) or had a general quantitative resistance against fungi. A series of experiments was carried out to assess the performance of the non-GM and GM lines without competition and in two different experimental weed communities in the field, their seed longevity in the soil under controlled conditions in the laboratory, seedling volunteering, persistence and over-winter survival in fallow plots in the field and the potential effects of these plants on post-harvest weed communities.

We asked the following questions: (1) how do GM plants perform (in terms of their yield, fitness-related traits and mildew infection) compared to their non-GM counterparts without competition and in the experimental weed communities common for wheat fields and wheat fallows? (2) Can the seeds of wheat persist in soil throughout winter and is seed longevity different between GM and conventional lines? (3) Do GM seedlings appear more often and do 
they persist longer than those of conventional wheat on post-harvest fallow plots? (4) Are there any post-harvest effects of wheat plants on fallow weed communities?

\section{Material and methods}

\section{Plant material}

We used six transgenic lines derived from two maternal varieties of spring wheat, the Mexican variety Bobwhite and the old Swiss variety Frisal. These two varieties were chosen because they show high transformation efficiency and are susceptible to powdery mildew pathogen (Bieri et al., 2003; Pellegrineschi et al., 2002). Furthermore, they are both susceptible to powdery mildew, yet to different degrees (Bobwhite>Frisal).

Four transgenic lines (Pm3b\#1-4) were produced by biolistic transformation of Bobwhite in different transformation events. The Pm3b gene was cloned from hexaploid wheat (Yahiaoui et al., 2004) under the control of the Zea mays L. ubiquitin promoter (Christensen and Quail, 1996) and confers race-specific resistance to powdery mildew. Transformants were selected on mannose-containing media using the phosphomannose isomerase (PMI)-coding gene as selectable marker (Reed et al., 2001). After regeneration of T0 transformants, four independent T1 families were selected. From each T1 family, an offspring pair was further propagated consisting of a homozygous transgenic plant (GM lines Pm3b\#1-4) and a null-segregant, i.e. a plant that did neither inherit the Pm3b transgene nor the selectable marker (control lines Sb\#14). The ubiquitin promoter from maize ensured high constitutive transgene expression. The seeds used in this study were obtained from homozygous GM and control lines that had passed through five generations of sexual reproduction by self-pollination.

The performance in monoculture under natural powdery mildew infection pressure in the field and the transgene expression of the lines Pm3b\#1-4 have been described by two companion studies (Brunner et al., 2011; Zeller et al., 2010). Pm3b\#1-3 lines carried a single copy of the transgene $P m 3 b$, and $P m 3 b \# 4$ line carried one full-length and one inactive truncated copy. The transgene expression levels were similar among Pm3b\#1, Pm3b\#3 and Pm3b\#4, while Pm3b\#2 line showed five times higher levels of expression. Partial gene silencing and consequent segregation in resistance were observed in the $P m 3 b \# 3$ line, where some plants showed high resistance and others were susceptible to mildew (Brunner et al., 2011).

The respective non-transgenic sister lines Sb\#1-4 were used as a control to ensure that any somaclonal variations acquired during tissue culturing were shared between transgenic and control lines. In the present study, we also used conventional wheat variety Bobwhite as an additional non-transgenic control (comparator) for Pm3b GM lines.

The GM lines derived from the variety Frisal expressed either a barley seed chitinase gene (line A9 Chi) or both a chitinase and a $\beta$-1,3-glucanase gene (Bieri et al., 2003; Leah et al., 1991). Quantitative resistance genes provide partial, and usually broad spectrum resistance against many races of one pathogen or even against different pathogens. Chitinases and glucanases are hydrolytic enzymes, able to degrade cell walls of fungi. The expression of these pathogenesis-related genes results in increased quantitative resistance to fungi, including mildew (Zhu et al., 1994). In an earlier study of Bieri et al. (1999), it has been shown that expression of both chitinase and B-1,3-glucanase genes caused higher reduction in mildew infection frequency on the leaves of wheat than expression of chitinase only. The seeds used for the experiments were obtained from the sixth generation of transgenic lines A13 Chi/Glu and A9 Chi. No transgene silencing occurred in these lines (C. Diaz Quijano et al., unpublished data). In the 
absence of sister lines that had undergone the same tissue culture as the transgenic Frisal lines, we used ordinary non-transgenic Frisal plants as the control line.

According to the guidance of the European Food Safety Authority for risk assessment of GM plants (EFSA, 2011), in addition to the comparison of GM plants to their appropriate conventional counterparts (test of difference), a comparison with the other conventional varieties (test of equivalence) is recommended. In addition to the 12 lines or varieties already mentioned, we used three commercialized conventional wheat varieties Casana, Fiorina and Toronit (in the following "lines and varieties" are referred to as "lines") as reference to verify whether the characteristics of the GM plants fall within the range of variation between conventional varieties of wheat, the criterion of the test of equivalence.

All GM lines were produced as model plants for the National Research Program 59 and were not intended for agricultural commercialization. The details on the plant material used are summarised in Table 1.

Table 1. Transgenic and control wheat lines used in the experiments.

\begin{tabular}{|c|c|c|c|}
\hline Line name & Variety (genetic base) & GM/non-GM (control) & $\begin{array}{l}\text { Transgene/s conferring } \\
\text { resistance }\end{array}$ \\
\hline$P m 3 b \# 1-4$ & Bobwhite & GM & $P m 3 b$ \\
\hline $\mathrm{Sb \# 1-4}$ & Bobwhite & $\begin{array}{l}\text { Non-GM, null-segregants, control } \\
\text { sister lines for } P m 3 b \text { lines }\end{array}$ & - \\
\hline Bobwhite & Bobwhite & $\begin{array}{l}\text { Non-GM, Mexican wheat variety } \\
\text { Bobwhite, mother variety for } P m 3 b \\
\text { and Sb lines }\end{array}$ & - \\
\hline A13 Chi/Glu & Frisal & GM & $\begin{array}{l}\text { Chitinase and } \beta-1,3- \\
\text { glucanase (Chi, Glu) }\end{array}$ \\
\hline A9 Chi & Frisal & GM & Chitinase (Chi) \\
\hline Frisal & Frisal & $\begin{array}{l}\text { Non-GM, mother variety for A9 } \\
\text { Chi and A13 Chi/Glu lines }\end{array}$ & - \\
\hline $\begin{array}{l}\text { Casana } \\
\text { Fiorina } \\
\text { Toronit }\end{array}$ & $\begin{array}{l}\text { Casana } \\
\text { Fiorina } \\
\text { Toronit }\end{array}$ & $\begin{array}{l}\text { Non-GM commercialized Swiss } \\
\text { wheat varieties }\end{array}$ & - \\
\hline
\end{tabular}

Performance of the wheat plants in weed communities and without competition

This field experiment took place in 2008 at ART Reckenholz research station in Zurich, Switzerland. In March 2008, two types of weed mixtures were sown in eight $7 \times 1.08 \mathrm{~m}$ plots arranged in a randomized complete block design with four replicate blocks. For the weed mixture\#1, the species typical for agricultural wheat fields were chosen; for the weed mixture\#2, the species commonly found in wheat-fallow fields (after harvest) in that area were selected (Table 2). In addition, one plot per block was left bare (no-competition environment). The plots were split into subplots.

Because nutrient availability is known to affect plant growth and competition mechanisms in plant communities (Casper and Jackson, 1997; Grace, 2012), the two $1 \times 1.08 \mathrm{~m}$ subplots of each plot were used for a split-plot treatment, i.e. fertilizer application vs. control. Fertilizer (“Ammonsalpeter 27.5", Lonza, Visp, Switzerland) was applied twice during the growing season (two times $3 \mathrm{~g} \mathrm{~N} \mathrm{~m}^{-2}$ ), randomly to one of the two subplots in each plot. The natural field soil 
provided the plants with sufficient phosphorous, potassium and magnesium (80, 235 and $234 \mathrm{mg}$ $\left.\mathrm{kg}^{-1}\right)$.

Table 2. The list of species sown in the weed mixture plots.

\begin{tabular}{ll}
\hline Weed mixture \#1 & Weed mixture \#2 \\
species common for wheat fields & species common for wheat fallows \\
\hline Apera spica-venti & Amaranthus retroflexus \\
Anagallis arvensis & Echinochloa crusgalli \\
Arabidopsis thaliana & Fumaria officinalis \\
Capsella bursa-pastoris & Galeopsis tetrahit \\
Centaurea cyanus & Lamium purpureum \\
Dactylis glomerata & Plantago lanceolata \\
Lolium perenne & Poa annua \\
Papaver rhoeas & Poa trivialis \\
Plantago major & Raphanus raphanistrum \\
Polygonum aviculare & Trifolium pratense \\
Trifolium repens & \\
\hline
\end{tabular}

In February 2008, 720 individual seeds of the 15 lines of T. aestivum (see "Plant material" section) were germinated in a climate-controlled glasshouse (day/night temperature: $21 / 16 \mathrm{C}^{\circ}$; additional light: $14 \mathrm{~h} / 10 \mathrm{~h}$ day/night period). In March 2008, the seedlings at phenological stage 11 (i.e. the first leaf unfolded) (Zadoks et al., 1974) were transplanted from the glasshouse to the field subplots with two different weed communities or empty subplots (no-competition control). These seedlings grown under standard conditions in the glasshouse were used to assess the performance of the GM and non-GM wheat lines in weed communities under two soil nutrient levels in the field.

Thirty seedlings representing 15 lines of T. aestivum were introduced into each $1 \times 1.08 \mathrm{~m}$ subplot. The seedlings were planted into six rows with a distance of $18 \mathrm{~cm}$ between the rows and $20 \mathrm{~cm}$ between the neighbouring wheat plants in a row (Table 3; Figures S1, S2 in Appendix A Supplementary data). Each wheat line was represented twice in each subplot (see also Kalinina $e t$ al. (2011)).

Table 3. Treatments applied to assess the performance of the GM and non-GM wheat plants in two weed communities and without competition.

\begin{tabular}{lll}
\hline Treatment & Applied at & Comparisons/treatment levels \\
\hline Competitive environments & Plot & Weed mixture\#1 \\
& & Weed mixture\#2 \\
& No competition \\
Fertilizer & Sub-plot & $\begin{array}{l}\text { No fertilizer } \\
\text { Wheat lines }\end{array}$ \\
& $\begin{array}{l}\text { Sub-plot (30 individual wheat } \\
\text { plants planted within each sub- } \\
\text { plot) }\end{array}$ & 15 GM and non-GM wheat lines \\
& & \\
\hline
\end{tabular}

The naturally emerging weeds were bi-weekly removed from the no-competition control plots but were left to grow in the weed mixture plots. These, however, had much lower abundance 
than the species sown intentionally. In June 2008, the weed species growing in the weed-mixture plots were identified. The detailed lists of the weed species sown and those that naturally emerged are provided in Table S1 in Appendix A Supplementary data.

We recorded the phenological stage of all plants according to the "Zadoks" scale (Zadoks et $a l .$, 1974) 80 days after planting. Powdery mildew infection was also assessed 80 days after planting, when infection reached its maximum, according to a two-digit scale, where the first digit gives the relative height of the disease on the plant and the second digit shows disease severity as a percentage (Eyal et al., 1987). Because the naturally occurring in the field mildew infection affected $16 \%$ of all the plants only and disease severity was low, the binary infection presence-absence data for each wheat line in each treatment were used for the additional statistical analysis and the percentage of plants infected was shown on the graphs.

After ripening, all wheat plants were cut at ground level and separated into vegetative and reproductive parts (spikes). The plant material was dried at $80 \mathrm{C}^{\circ}$ (vegetative parts) or $25 \mathrm{C}^{\circ}$ (reproductive parts) and weighed. We threshed the spikes, determined the seed number per plant and obtained the total mass of all seeds per plant. The biomass allocation to seeds was calculated as a percentage of aboveground plant biomass. Henceforth, the seed number per plant is called "seed number" and biomass allocation to seeds is called "biomass allocation".

Data were analyzed with classical mixed-model analysis of variance (ANOVA) using the statistical software GenStat (GenStat v13.1.44, VSN International Ldt.). The treatment model consisted of the factorially-crossed wheat lines and environments (i.e. two weed mixtures and no-competition control) and fertilizer application. The error model consisted of the wheat lines nested within subplots, subplots nested within plots and plots nested within blocks. The terms of the treatment model were tested against the appropriate terms of the error model: environment varied among plots, fertilizer application among subplots and wheat line within subplots. For the analysis, the seed-number data were log-transformed. The data were analyzed for all the environments together to test the main effects and also for the two weed and no-competition environments separately. The structure of the comparisons for the alternative models used is shown in Figure S3 in Appendix A Supplementary data. The binary mildew incidence data were analyzed using multiple logistic regression with mixed-model analysis of deviance (McCullagh and Nelder, 1989).

\section{Seed persistence in the soil}

The seeds of the 15 wheat lines for this experiment were obtained from the NRP59 field trial 2008 (Zeller et al., 2010). Half of the seeds were from the plants which did not receive fertilizer in the field and the other half from the plants fertilized twice during the growing season 2008 (3 $\mathrm{g} \mathrm{N} \mathrm{m}^{-2}$ as "Ammonsalpeter 27.5", Lonza, Visp, Switzerland). Because the biosafety regulations prohibited putting the seeds of GM plants into soil in the field additionally after harvest, the experiment on seed persistence was performed under controlled conditions in climate chamber. The seeds of the wheat lines were stored in a ventilated chamber in the laboratory at $\mathrm{T}=6^{0} \mathrm{C}$ in complete darkness (the temperature was chosen based on the average winter soil temperature 5 $\mathrm{cm}$ below ground in that region) for three or for six months.

Before setting up the seed persistence experiment, initial germination rates were tested in Petri dishes in five replicates in the glasshouse. Twenty seeds were placed into each Petri dish $(\varnothing 10$ $\mathrm{cm}$ ) on filter paper resulting in 100 seeds per wheat line in total. The Petri dishes were randomized and watered regularly. Germination rates were recorded every three days as a percentage of seeds germinated. 
For the seed persistence experiment, 20 seeds were placed into each Petri dish filled with dry (17.6\% humidity) and wet (77.5\% humidity) Ökohum lawn soil (Ökohum AG, Herrenhof, Switzerland).

Half of the seeds were kept in aerobic and another half in anaerobic conditions. To maintain anaerobic conditions, the Petri dishes were placed into polyethylene airproof bags sealed with vacuum sealer. Thirty Petri dishes (15 wheat lines $\times$ two mother-plant nutrient levels) were placed into each bag together with two sulfur-free oxygen absorbers (ATCO FTM 2000S, Long life for art, Germany). The air in the bags was replaced by nitrogen dioxide with a water jet vacuum needle, and then nitrogen dioxide was also removed. For the aerobic treatment, the bags with Petri dishes were left open.

Half of the bags were stored for 3 months and another half for 6 months, the approximate time after harvest needed for seeds to germinate in autumn or in spring, in the laboratory. Altogether, there were five replicate Petri dishes and 100 seeds per mother-plant nutrient level $\times$ wheat line $\times$ time of storage $\times$ storage condition combination. After 3 and 6 months, respectively, the seeds were removed from Petri dishes, washed and the number of seeds germinated during storage was recorded. Seeds that did not germinate during storage were placed into new Petri dishes for germination tests, performed in the same way as the initial germination tests.

\section{Monitoring of seedling persistence in the field}

From March until August 2008, the 15 wheat lines (see Plant material section) were grown in 120 field plots of $1 \times 1.08 \mathrm{~m}$ size at ART Reckenholz research station in Zurich, Switzerland. In each plot 400 wheat seeds were sown in six rows with a distance of $18 \mathrm{~cm}$ between rows (Zeller et al., 2010).

The plots were arranged in four blocks. Half of the plots were fertilized twice during the growing season ( $3 \mathrm{~g} \mathrm{~N} / \mathrm{m}^{2}$ as "Ammonsalpeter 27.5", Lonza, Visp, Switzerland), the other half was left untreated.

In August 2008, the plants were harvested by hand (cut at soil level). Starting from the end of September 2008 and until the end of March 2009, we monitored the emergence of wheat seedlings from the seeds naturally shed to the soil surface and followed their growth and survival.

We distinguished three categories of "emergence events": the seedlings that emerged from single seeds ("individual seedlings"), the whole spikes germinated ("patches of seedlings") and new tillers coming from the plants cut at a ground level. Since it was not possible to distinguish individual plants in a dense patch, each germinated spike was counted as a single emergence event. In case of new tillers, each individual plant which formed one to several new tillers was counted as an individual emergence event.

In September 2008, all the emergence events were counted and 15 randomly selected individual seedlings (i.e. emerged from single seeds) per plot were marked with plastic labels indicating the date of count in order to follow up their survival over winter. During the following five census counts in October, November, January, February and March we recorded the number of the marked individual seedlings that persisted in the field and counted the total number of the individual seedlings, patches of seedlings and tillers per plot, including those which emerged after the initial count in September 2008.

Seedling mortality data were analyzed with generalized linear mixed-effects models (GLMM) with binomial errors and logit link using GenStat software (GenStat v13.1.44, VSN International Ldt.). Seedling mortality rates presented in figures were calculated as a percentage of dead 
seedlings at the end of a time interval out of those that were still alive at the beginning of the interval.

Vegetation analysis of the post-harvest weed communities

In November 2008 and in March 2009, we assessed and analyzed the weed communities established in the subplots where 15 different GM and conventional wheat lines were grown in spring-summer 2008 (the same $1.08 \mathrm{~m}^{2}$ subplots used for the monitoring of seedling persistence). Species richness (the number of species present), species abundance according to a multilevel scale (Braun-Blanquet, 1932) and total canopy cover in percentage were recorded for every subplot.

For the analysis, the original Braun-Blanquet scale was transformed to cover percentage, with total species cover values ranging from 0.6 to $160 \%$ (van der Maarel, 2007). ShannonWiener diversity indices (Kent and Coker, 1992) were calculated for every subplot. The postharvest effects of the wheat lines and fertilization on species richness, species abundance, total canopy cover and the abundance of the four dominant weed species were investigated with mixed-model ANOVAs (see previous section).

The binary data of the occurrence of the four dominant species were analyzed with mixedmodel analysis of deviance. The composition of the entire weed community was analyzed with principal coordinate analysis (PCO) of Euclidean and Jaccard similarity matrices with GenStat software (GenStat v13.1.44, VSN International Ldt.).

\section{Results and discussion}

\section{Plant performance in weed communities and without competition}

The first our research question was whether transgenic wheat plants have a better performance than conventional ones in the field when grown without competition or in experimental weed communities. To address this question, a number of fitness-related traits were assessed and powdery mildew infection has been scored on the wheat plants in the field.

\section{Mildew infection}

Natural mildew infection occurred on $16 \%$ of all the plants assessed. On the infected plants, the disease severity (i.e. the percentage of a plant surface affected, corresponds to the second digit of the 2-digit scale) did not differ significantly between the treatments or wheat lines and reached $21.5 \%$ on average.

The height of infection on the infected plants (the first digit of the disease assessment scale; see Eyal et al. (1973)) reached on average 52,7\% and varied significantly between the nocompetition environment and weed mixtures, being $8 \%$ higher in no-competition plots $(P=0.012)$. The height of infection spread on the infected wheat plants in weed mixture\#1 by $14,5 \%$ exceeded that in the weed mixture\#2, where taller plant species (Amaranthus retroflexus and Echinochloa crusgalli) formed higher canopies (weed mixture\#1 vs. weed mixture\#2 contrast: $P=0.037)$. Transgenic $P m 3 b$ wheat lines showed $13 \%$ lower height of the infection spread than the corresponding sister lines $(P=0.008)$ and $14.3 \%$ lower height of infection than the mother variety Bobwhite $(P=0.05)$. No differences in the height of infection on the plants were observed between the Frisal mother variety and Frisal-derived GM lines or between the three commercialized Swiss wheat varieties. Fertilizer application enhanced the height of powdery mildew spread on plants 1.4 -fold $(P=0.004)$ but did not affect the differences between GM and non-GM wheat lines. 
Mildew incidence (here, the percentage of the infected plants out of total plants assessed) was 1.6-fold lower when wheat plants were grown with competitors (weeds) than when planted alone (no competition vs. weed competition contrast: $P=0.042$; Figure 1; Table $S 2$ in Appendix A Supplementary data). Because no significant differences in mildew incidence or wheat plant performance were found between the two tested weed mixtures, the data for these competitive environments are pooled in Figure 1.

Interestingly, the wheat plants were infected by powdery mildew less frequently and showed lower infection severity when grown in diverse weed communities, which supports the view that pathogen transmission and infection may be regulated by plant community characteristics, such as species diversity, and that pathogen incidence can be reduced with increasing diversity (Mundt, 2002; Rottstock et al., 2014; Wolfe, 2000; Zeller et al., 2012; Zhu et al., 2000). Monoculture fields seem to lead to higher disease infection, while species mixtures could be advantageous for disease suppression, given that the diversity and plant density in mixtures will be maintained at a level where these do not negatively affect plant fitness traits. Additionally, a physical protective effect of the dense weed canopies compared to more "open" no-competition plots could play a role (Finckh et al., 2002; Trenbath, 1977). Transgenic Pm3b lines showed up to five-fold lower mildew incidence than corresponding control $\mathrm{Sb}$ lines ( $P m 3 b \mathrm{vs}$. Sb lines contrast: $P<0.001)$ and also significantly lower mildew incidence than that of the mother variety Bobwhite $(\mathrm{P}<0.001)$. Each of the four GM Pm3b lines had significantly lower mildew incidence than the corresponding sister line (see pairwise comparisons in Table S2) or Bobwhite. Similar to the Bobwhite variety mildew incidence was only observed in Pm3b\#4 GM line in nocompetition plots. A line with high transgene expression, $P m 3 b \# 2$, had even lower mildew incidence than the other three $P m 3 b$ lines ( $P m 3 b$ lines contrast: $P=0.043$ ). Interestingly, Sb lines showed on average higher mildew incidence than the conventional mother variety Bobwhite ( $\mathrm{Sb}$ lines vs. Bobwhite contrast: $P=0.002$ ). Earlier, in a similar field experiment with the same wheat lines, we observed other differences in morphology and yield between the lines which passed through genetic transformation (Zeller et al., 2010), indicating that transformation process, tissue culturing or transgene insertion may have unintended effects on plant performance.

Transgenic lines A9 Chi and A13 Chi/Glu had lower mildew incidence than their mother variety Frisal when grown without competition (A9 Chi and A13 Chi/Glu vs. Frisal contrast: $P=0.004)$ : line A9 Chi was not infected and line A13 Chi/Glu had 3.5-fold lower mildew incidence than Frisal (Figure 1); and none of the A9 Chi, A13 Chi/Glu or Frisal plants were infected when planted in weed communities.

Three modern commercial Swiss wheat varieties Casana, Fiorina and Toronit had overall low powdery mildew incidence in the field, comparable with that of the Pm3b GM lines (Pm3b lines vs. Swiss varieties contrast: $P=0.96)$, indicating that conventional wheat varieties currently used in agriculture already possess a certain degree of resistance to mildew pathogen.

Fertilizer application increased overall mildew incidence 2.5-fold (main fertilizer effect: $P=0.013$ ) but did not affect the differences between GM and non-GM wheat lines.

Fitness-related traits

The canopy cover in all the plots sown with the weed mixtures was $100 \%$ creating a strong competitive environment for the wheat plants and affecting the seed number and other fitnessrelated traits. Weed competition caused an overall 2.2-fold decrease in seed number and 1.8-fold decrease in tiller number of the wheat lines compared to the control subplots without competition 
(no-competition vs. weed competition contrast: $P=0.001$ for seed number, $P=0.004$ for tiller number).

Transgenic $P m 3 b$ lines had overall a 1.6-fold lower seed number ( $P m 3 b$ vs. Sb lines contrast: $P<0.001), 1.1$-fold lower biomass allocation $(P=0.013)$ and 1.1 -fold lower plant height $(P=0.006)$ than the $\mathrm{Sb}$ control sister lines. Similar differences in seed number and plant height were observed when $P m 3 b$ lines were compared with Bobwhite $(P=0.006$ for plant height; $P<0.001$ for seed number). These differences were more pronounced in weed environments ( $P m 3 b$ vs. Sb lines contrast in weed environments: $P=0.031$ for plant height, $P<0.001$ for seed number, $P=0.002$ for biomass allocation) and were insignificant ( $P m 3 b$ vs. Sb lines contrast in no-competition environment: $P=0.084$ for plant height, $P=0.37$ for biomass allocation) or less pronounced ( $P=0.004$ for seed number) when plants were grown without competition. Only line $P m 3 b \# 4$ had significantly lower seed number than its control when grown in no-competition plots ( $P m 3 b \# 4$ vs. Sb\#4 contrast in no-competition environment: $P<0.001)$. The other three $P m 3 b$ lines had reduced seed number compared to corresponding sister lines only when planted in weed communities ( $P m 3 b \# 1$ vs. $S b \# 1$ contrast in weed environments: $P=0.01 ; P m 3 b \# 2$ vs. Sb\#2: $P<0.001$; $P m 3 b \# 4$ vs. Sb\#4: $P=0.003)$, with line $P m 3 b \# 2$ showing the highest, 2.8 -fold, reduction in seed number among the other lines.

None of the $P m 3 b$ lines differed from sister lines or Bobwhite in tiller number and in plant height when planted without competition. In weed communities, however, line Pm3b\#2 had 1.4fold reduced tiller number compared with line $\mathrm{Sb \# 2} \mathrm{(} P m 3 b \# 2$ vs. Sb\#2 contrast: $P=0.046$ ); line $P m 3 b \# 1$ had 1.2-fold and line $P m 3 b \# 2$ had 1.1-fold reduced plant height compared with the corresponding sister lines $(P m 3 b \# 1$ vs. $\mathrm{Sb \# 1}$ contrast: $P=0.004 ; P m 3 b \# 2$ vs. $\mathrm{Sb \# 2}$ contrast: $P=0.05)$.

There were no differences in phenological stage between GM and control wheat lines or Bobwhite, with the exception of line Pm3b\#4, which had less advanced phenological stage than its corresponding sister line in control plots ( $P m 3 b \# 4$ vs. Sb\#4 contrast in no-competition environment: $P<0.001)$.

The four $P m 3 b$ wheat lines differed significantly in their seed number, plant height and phenological stage $(P=0.004, P=0.003, P=0.039$ for seed number, plant height and phenological stage, respectively). Overall, the lines $P m 3 b \# 2$ and $P m 3 b \# 4$ had lower seed number than the other two GM lines. Pm3b\#2 showed also lower plant height than the other $P m 3 b$ lines. The differences in seed number, biomass allocation and plant height between the transgenic Pm $3 b$ and control lines exceeded those between the three commercialized conventional wheat varieties (\%SS in Tables S2-4 in Appendix A Supplementary data).

Summarizing these findings, both GM and non-GM wheat lines had weaker performance under competition with weeds than when they were grown without competitors. The GM lines carrying the $P m 3 b$ transgene, however, showed fitness reductions compared to non-GM lines when grown in the weed communities and did not differ or differed less from the controls when grown alone. These results correspond well with the results of previous assessments of performance of the same wheat lines under competition in different wheat crop stands (assessed in the same type of the experimental setting the same year), where the fitness disadvantages of resistant GM plants also became more evident under stronger competition (Kalinina et al., 2011).

Our finding supports the view that costs of resistance can be more apparent under conditions of abiotic or biotic stress (DeWitt et al., 1998; Van Dam and Baldwin, 2001). As shown by Dewitt et al. (1998), costs are more likely to be seen when plants are forced to deploy several phenotypic responses simultaneously, so that internal resource trade-offs limit performance 
(DeWitt et al., 1998). In our study, lower reproductive output of GM lines under competition with weeds could possibly be due to the simultaneous response of the wheat plants to competition and the constitutive expression of pathogen defense, which could divert resources from the processes involved in reproduction (DeWitt et al., 1998; Tollrian and Harvell, 1999). The reductions in seed number and biomass allocation to seed were particularly severe in the GM line $P m 3 b \# 2$, for which a five-fold higher transgene expression has been reported (assessment done in 2008 in the same field) than for the other Pm3b GM lines, whereas the GM line Pm3b\#3, known for segregation in resistance (Brunner et al., 2011), did not differ from the corresponding non-GM line. This supports previous suggestions that the magnitude of the cost of resistance could be related to the level of transgene expression (Kalinina et al., 2011; Zeller et al., 2012).

Fertilizer application led to a 1.4-fold increase in seed number, a 1.2-fold increase in plant height and a 1.5-fold increase in tiller number (fertilizer effect: $P=0.025, P=0.001$ and $P<0.001$ for seed number, plant height and tiller number, respectively) and did not affect biomass allocation and phenological stage of the wheat plants. Fertilizer treatment did not affect the differences observed between the GM and non-GM wheat lines.

Under low pathogen pressure in the field, the incidence of mildew infection did not seem to affect the plant fitness-related traits such as, for instance, seed number. Competition with weeds and fertilizer application, instead, significantly affected seed number and some other traits across the wheat lines and were more significant yield-affecting factors than powdery mildew.

Because transgenic wheat lines neither grew better nor produced more seeds than non-GM lines, the risk that GM wheat plants used in this study would persist among weeds is not higher than for the corresponding non-GM lines. Nevertheless, also transgenic plants, like non-GM plants, were able to grow and successfully reproduce under conditions of $100 \%$ weed cover. Thus, if GM plants would germinate from seeds in the field after harvest or escape from a crop field to natural habitats, they would have the potential to reproduce and persist in weed communities. A thorough control of the GM-wheat fallow and adjacent areas, therefore, would be advisable.

Although wheat is a predominantly self-pollinating species (Hancock, 2003), the recent studies confirmed that outcrossing and gene flow to crop and wild relatives indeed occur in wheat in considerebale quantities and can be a path of the transgene transfer from GM wheat to non-GM crops or wild relatives (Guadagnuolo et al., 2001; Pajkovic at al., 2014; Rieben et al., 2011; Sun et al., 2015; Waines and Hegde, 2003). Therefore for wheat, as for most crops, persistence in the field can increase the risk of gene flow and consecutive spread of engineered genes into crop or wild populations (Ellstrand, 2003a,b). Our results indicate that transgenic wheat generally can grow in weedy habitats and has a potential to persist and produce seeds among weeds. To assess the longer-time consequences of this, multi-year experiments would be necessary.

\section{Seed persistence in the soil}

Our second question was whether seeds of GM wheat lines can persist in soil throughout winter and whether the seed longevity is different for GM and non-GM lines. To address this question, the aerobic and anaerobic storage conditions were manipulated in the laboratory and the seeds of the 15 wheat lines were stored in soil for 3 or 6 months. 
The average initial seed germination rate assessed before storage was $97.4 \%$ and did not differ between the tested wheat lines, except the conventional variety Fiorina which had significantly lower initial germination rate $(91 \%)$ than the other lines and varieties $(P=0.007)$.

On average, $87.0 \%$ of all the seeds germinated during storage in soil. The seeds that did not germinate during storage also did not germinate later in the germination tests and were considered to be not viable. More seeds $(91.0 \%)$ germinated in the Petri dishes stored for a period of 6 months than in those stored for 3 months (83.0\%; time of storage main effect: $P<0.001$; Table S5 in Appendix A Supplementary data).

Soil oxygen conditions and humidity played an important role for seed germination. A higher seed germination rate was observed in aerobic than in anaerobic conditions $(97.2 \mathrm{vs} .76 .7 \%$; aerobic vs. anaerobic conditions contrast: $P<0.001)$. Moreover, the roots were growing for a longer period of time and, according to visual observations, appeared to be longer under aerobic than under anaerobic conditions. Overall, more seeds germinated in dry soil than in wet soil (soil humidity main effect: $P<0.001)$.

Water excess in soil was in general advantageous for the germination of wheat seeds in aerobic conditions: more seeds germinated in wet soil than in dry soil. In anaerobic conditions, however, water caused a decrease in seed germination (interaction aerobic vs. anaerobic condition $\times$ soil humidity: $P<0.001$; see Table S5). This might be related to the oxygen shortage in wet soil, whereas $17.6 \%$ of soil humidity in the dry soil treatment was sufficient for seeds to germinate. Some studies suggest that wheat is especially sensitive to anaerobic conditions (Menegus et al., 1991) and wheat seeds are not able to germinate or the roots die fast after germination under anoxia (Morinaga, 1926; Perata et al., 1992).

Overall, we found no differences in seed persistence in soil between GM and non-GM wheat lines in response to soil oxygen and humidity stress. Only the line with high transgene expression Pm3b\#2 showed lower seed germination (92.2\%) compared to the corresponding non-GM Sb\#2 line $(98.2 \%)$ in dry soil under aerobic conditions of storage (Pm3b\#2 vs. Sb\#2 line contrast in aerobic conditions: $P<0.001$; interaction $P m 3 b \# 2$ vs. Sb\# $2 \times$ Soil humidity in aerobic conditions: $P=0.015)$. The three conventional Swiss wheat varieties differed in their seed germination during storage (3 Swiss varieties contrast: $P<0.001)$. Overall, Fiorina and Toronit had lower seed germination rate during storage in soil $(84.8 \%$ and $87.5 \%$, respectively) than the variety Casana $(92.5 \%)$. We also observed varietal differences in the response to oxygen content in soil (interaction 3 Swiss varieties $\times$ aerobic vs. anaerobic conditions: $P=0.013$ ). Under aerobic conditions, the three varieties had similar germination rates $(96.4 \%, 95.6 \%$ and $97.4 \%$ for Toronit, Fiorina and Casana, respectively), whereas under anaerobic conditions Fiorina showed 8.9\% lower germination ability compared to the other two Swiss wheat varieties (interaction 3 Swiss varieties $\times$ aerobic vs. anaerobic conditions: $P<0.001$ ).

Whether the maternal plants received additional nutrients or not (main fertilizer effect) did not affect the initial germination ability of the seeds or their germination during storage (see Table S5).

We found no indication that seeds of the studied GM lines could persist longer in soil than the seeds of their corresponding non-GM lines at given humidity, oxygen and temperature conditions. Studies on other GM crops, e.g. on herbicide-tolerant oilseed rape, also showed that GM lines had no advantage compared to conventional varieties in their seed persistence in soil (Gruber et al., 2004; Lutman et al., 2005). Moreover, in our experiment one of the GM lines (Pm3b\#2) known for high transgene overexpression (Brunner et al., 2011; Kalinina et al., 2011; Zeller et al., 2010) showed lower seed germination than its corresponding control line. Lower 
germination rates for GM compared with non-GM plants were earlier reported for transgenic rape in a seed burial study (Hails et al., 1997). One of the explanations might be physiological costs associated with the constitutive transgene expression or pleiotropic effects of the transgene which could potentially affect seed viability. For the GM wheat line Pm3b\#2, we have previously observed and reported unintended phenotypic changes, such as chlorophyll deficiency, lower seed set, reduced agronomic yield and weaker competitive performance (Brunner et al., 2011; Kalinina et al., 2011; Zeller et al., 2010).

In our experiment, most of the seeds either germinated quickly or lost their viability after 3 months of storage in soil. This supports the results of some other studies which have shown that a persistent seed bank in soil is not common for wheat cultivars (Harker et al., 2005a; Nielson et al., 2009). Nielson et al. (2009), for example, reported a 99\% loss of seed viability for conventional cultivars of Canadian spring wheat within 6 months after seed burial in the field (Nielson et al., 2009).

\section{Seedling persistence in the field}

Our third question was whether seedlings of GM wheat appear more often and persist longer than those of conventional wheat in post-harvest weed communities. To address this question we assessed the emergence and persistence of the seedlings of 15 wheat lines which emerged in the field after harvest. Volunteering wheat plants, however, were represented not only by seedlings coming from individual seeds lost at harvest. Therefore, we additionally assessed the persistence of dense patches of seedlings germinating from whole spikes (the number of patches persisting was counted) and tillers which emerged from the plants cut at harvest (here the number of plants with such tillers was counted).

Despite the biosafety measures undertaken at harvest, such as harvesting individual plants by hand and collecting seeds from the soil surface, in total, 1053 emergence events (i.e. individual seedlings, patches of seedlings and tillers) occurred in the $129.6 \mathrm{~m}^{2}$ of the field monitored during 6 months after harvest. Of these emergence events, 88.6\% were individual seedlings coming from single seeds, $6.4 \%$ were whole spikes germinated (the number of patches of seedlings was counted), and 5\% were new tillers coming from the base of harvested plants cut at ground level.

Due to low rates of after-harvest tiller development, tillering does not appear to be an important mechanism of wheat persistence in the field. The emergence of patches of seedlings from the spikes also occurred rarely. The patches of seedlings, however, had a higher survival rate (82.1\% survived for 6 months until the end of monitoring in March) than individual seedlings $(56.3 \%)$ or tillers $(52.8 \%)$, i.e. when a dense group of seedlings emerged there was a high probability that at least some plants from this group persisted for a longer period of time (Figure S4 in Appendix A Supplementary data).

The vast majority of all the emergence events (87.3\%) occurred in September 2008, one month after harvest, $10.7 \%$ occurred in October 2008 and $1.3 \%$ in November 2008. We observed no further plant emergence after November.

During the 6 month period of monitoring, 32 wheat plants which persisted in the field formed spikes; $87.5 \%$ of these developed spikes within the first two months after harvest and the rest formed spikes in the following spring. Twelve out of the 32 plants which developed spikes were transgenic.

The number of tillers and germinated patches of seedlings did not differ between GM and control plots. Although $25.9 \%$ more individual seedlings emerged in the plots where control Sb lines were grown than in those with $P m 3 b$ transgenic lines (Pm3b vs. Sb lines contrast: 
$P=0.018$ ), this effect could be a result of a 2-3 days earlier harvesting of transgenic plants due to biosafety considerations, and thus of a more advanced ripening stage and consequently higher seed loss for non-GM wheat lines by the time of harvest.

Three commercialized conventional wheat varieties Casana, Fiorina and Toronit differed significantly in their post-harvest tiller development ( 3 Swiss wheat varieties contrast: $P<0.001$ ), Fiorina showing lower new tiller emergence than the other two varieties.

Fertilization applied during the preceding field season (2008) did not influence the number of the emergence events.

The individual seedlings emerged in the field in September 2008 were labeled (15 plants per plot; see Materials and methods section) and their mortality and persistence were surveyed for 6 months, until March 2009. Seedling mortality logically increased with the length of the observation interval (days between counts effect: $P<0.001$; Table S6 in Appendix A Supplementary data) and showed a rapid increase 161 days after harvest, at the fifth monitoring count on January 24, 2009 (time effect: $P<0.001$; Figure 2). This increase in mortality coincided with lower air and soil temperatures and a decrease in precipitation during the winter months (Figure 2).

Transgenic lines did not differ significantly from the corresponding control lines in seedling mortality rates (Table S6 in Appendix A Supplementary data).

The surveyed seedlings of the three modern Swiss wheat varieties Toronit, Casana and Fiorina showed significantly lower mortality rates than the average of the other lines (Swiss vs. other wheat contrast: $P=0.002$ ). The Mexican variety Bobwhite and the lines derived from it had much higher mortality in the field than the old Swiss variety Frisal and its two GM lines A9 Chi and A13 Chi/Glu (Bobwhite vs. Frisal contrast: $P<0.001$ ).

Of the total of 810 individual seedlings labeled in September 2008 and surveyed, 53.3\% (432) survived winter and were persisting in the field 6 months after emergence, in March 2009.

Among the surveyed individual seedlings, there were 193 Pm3b GM plants and $33.7 \%$ of these persisted until March. The number of emerging control Sb seedlings was 256 and $42.2 \%$ of them persisted until spring. The number of emerging transgenic Frisal seedlings was 98 and $76.5 \%$ of them persisted for 6 months until March. Among the 63 labeled individual seedlings of control Frisal line, $71.4 \%$ persisted until the end of monitoring.

Thus, we found no indication that the individual seedlings of GM lines could persist in the field longer than the seedlings of their corresponding non-GM lines. However, 140 transgenic wheat plants were found to survive over winter and to persist until spring and 12 GM plants even formed spikes. Unfortunately, but necessarily for biosafety reasons, it was not possible to monitor these plants for a longer time period to assess the next year rates of re-seeding from the wheat plants persisting in the field; they had to be destroyed before flower opening.

We observed strong varietal differences in volunteer seedling mortality: the plants originating from Swiss varieties were better adapted to low winter temperatures and had lower mortality rates than the plants of the Mexican wheat variety Bobwhite. Thus adaptation to local environmental conditions appeared to be a more important predictor of overwinter survival than the presence of transgenes in a plant, at least in the context of this study. Several other studies have previously reported high variability in volunteer (self-sown) seedling emergence and persistence of GM and non-GM wheat or GM and non-GM lines of other crops in the field depending on genotypic, environmental or production factors (Anderson and Soper, 2003; De Corby et al., 2007; Gruber et al., 2004; Harker et al., 2005a). Although in our study there were no differences in persistence of the transgenic disease-resistant and non-GM lines, some other 
types of transgenes, in particular genes that confer resistance to herbicides, may be more likely to enhance persistence of GM plants in fallow fields. In Canada, for example, glyphosate-resistant wheat recruitment was observed in the field even 3 years after sowing and the recruitment rates strongly depended on agricultural practice, i.e. tillage and herbicide application (Harker et al., 2005a). Some studies also reported long-term persistence of herbicide-resistant oilseed rape in or outside agricultural habitats (D'Hertefeldt et al., 2008). Other new transgenes, such as those modifying seed quality or increasing overall plant fitness, are also expected to have more positive effects on persistence of GM wheat plants through increasing seed or plant survival and fecundity (Claessen et al., 2005). It is therefore difficult to predict potential persistence and overwinter survival of new transgenic wheat varieties which would have to pass the environmental risk assessment (ERA) on a case-by-case basis. The strong varietal differences in persistence also indicate that GM traits should preferably be bred into varieties with low persistence in crop and wild habitats.

Interestingly, we observed continuous wheat seedling emergence from September until November 2008 but not later, in spring 2009. Because we have only assessed seedling emergence until April 2009, we cannot exclude the possibility that wheat seeds would also germinate in the field later, when soil temperatures rise. The short life of wheat seeds in soil (see above the discussion of seed persistence in soil in the laboratory), however, indicates that newly emerged seedlings would rather result from a re-seeding by volunteer plants than from the soil seed bank. Although some studies reported the emergence of seedlings of GM wheat in the field after 16 months to 3 years after harvest (De Corby et al., 2007; Harker et al., 2005a), these volunteering events may have resulted from re-seeding by volunteer wheat plants and may be influenced by agricultural practice (Harker et al., 2005a). Our data support the point of view that the establishment of escaped volunteer plants with subsequent re-seeding may be a more important persistence mechanism for spring wheat in the field than the fast-decaying soil seed bank could be (De Corby et al., 2007).

\section{Post-harvest weed vegetation}

The fourth question we asked was whether GM wheat cultivation might affect the structure of the post-harvest weed communities.

We found 47 species growing in the plots in autumn 2008 and 30 species in spring 2009 (Table S7 in Appendix A Supplementary data). The dominant species were Seneceo vulgaris L., Poa annua L. and Veronica persica Poir. with 2.5, 1.9 and $1.7 \%$ average plot canopy cover, respectively. In autumn, $P$. annua was more abundant in previously fertilized plots $(P=0.035)$. This confirms the results of the other studies showing that grasses often benefit from fertilization and become dominant in plant communities in fertilized habitats at the expense of other species (Foster and Gross, 1998; Mountford et al., 1993). There were no other effects of fertilization, wheat line or the time of count on the abundance of the dominant species.

The principal coordinate analysis (PCO) of Euclidean distances and Jaccard similarity matrices of the two vegetation counts showed no difference in vegetation composition between the plots where transgenic lines had been grown and those where conventional wheat lines had been grown prior to the monitoring (Figure 3). Fertilizer application during the vegetation season 2008 also had no effect on post-harvest weed community composition in the plots. Although the PCO of Euclidean distances showed a clustered pattern, this clustering was not due to the wheat line, fertilizer application or block effects. 
Species richness, Shannon-Wiener diversity and total canopy cover also did not differ between the plots previously planted with transgenic or conventional wheat lines (Tables S8-S10 in Appendix A Supplementary data).

Thus, we found no differential effects of growing GM vs. non-GM wheat on the diversity or structure of the fallow weed communities. The known effects on post-harvest vegetation of some GM crops, in particular those with introduced herbicide resistance (Harker et al., 2005b) can be largely caused by the agricultural practice, i.e. herbicide application, used with such crops and not directly by the transgenes. However, GM plants have also a potential to impact vegetation indirectly, affecting soil microorganisms, non-target insect herbivores or through the persistence of the transgene product in soil (Dale et al., 2002; Gyamfi et al., 2002; Hilbeck, 2001; Snow et $a l ., 2003)$. In our case, however, the wheat plants carrying Pm3b and Chi and Glu transgenes did not seem to change the post-harvest vegetation, at least within the 6-month time period. Our findings correspond to the results of several companion studies which showed no effects of these particular GM plants on non-target organisms, such as insect species (Alvarez-Alfageme et al., 2011; Peter et al., 2010; von Burg et al., 2010), soil fauna (Duc et al., 2011) or soil beneficial bacteria and mycorrhizal fungi (Meyer et al., 2013; Song Wilson et al., 2010).

In November 2008, three months after harvest, we observed a marginally significant effect of fertilization on the diversity of the weed communities (species richness): $6.8 \%$ more species were found in unfertilized plots compared to the plots that had been fertilized. This supports the theory that soil nitrification negatively affects species diversity (Elisseou et al., 1995; Mountford et al., 1993; Willems et al., 1993). This effect, however, disappeared by spring 2009, when fertilizer left in the soil after the field season had probably fully been taken up by plants or washed out from the soil. There was no indication that GM lines responded differently from nonGM lines to nitrogen fertilization.

\section{Conclusions}

The introduced transgenes conferring resistance to pathogenic fungi did not enhance the persistence of GM wheat plants compared to the non-GM plants in weed communities commonly associated with wheat or on fallow plots. Rather, some transgenic plants even showed fitness costs when they had to withstand competition from weeds. Growing transgenic wheat lines had also no effect on the structure and diversity of the fallow weed communities. Our study shows, however, that GM wheat plants are able to persist and reproduce both among weeds and in the fallow over winter. Fast seed germination and short-term seed persistence in soil along with successful overwintering indicate that persistence of the seedlings and plants of transgenic wheat in fallow fields and subsequent re-seeding might be a more important mechanism of GM wheat persistence than germination from the soil seed bank. Strong varietal differences in persistence point out the importance of case-by-case environmental risk assessment of new GM wheat varieties and indicate that GM traits should preferably be bred into varieties with low persistence.

\section{Acknowledgements}

We thank S. Brunner, B. Keller, C. Sautter, J. Fütterer and A. Fammartino for seed material; the ART Reckenholz research station in Zurich, Switzerland, for setting up the field trial; the Federal Office of Meteorology and Climatology of Switzerland for providing the meteodata; T. Arslan for her contribution to the seed persistence experiment; M. Nuñez-Marce for volunteering and I. Kostetskyi and numerous helpers for assistance in the field. 
This project was supported by the Swiss National Science Foundation (SNF 405940-115607) and was part of the wheat-cluster.ch, a sub-unit of the Swiss National Research Program 59 "Benefits and risks of the deliberate release of genetically modified plants" (www.NRP59.ch). The funders had no role in study design, data collection and analysis, decision to publish, or preparation of the manuscript. 


\section{Appendix A. Supplementary data}

Supplementary data associated with this article can be found in the online version.

Table S1. Weed species which were sown or naturally occurred in weed mixture plots.

Figure S1. Scheme of the "weed" experiment.

Figure S2. Photograph of the weed mixture plot with wheat plants.

Figure S3. The structure of orthogonal contrasts used in the extended ANOVA models.

Tables S2-S4. ANOVA tables showing effects of weed competition and fertilizer applied during the preceding field season on mildew incidence, morphological traits and biomass allocation of $15 \mathrm{GM}$ and non-GM wheat lines.

Table S5. ANOVA table showing effects of time, oxygen availability, soil humidity and fertilizer obtained by the mother plant on the percentage of seeds of 15 wheat lines germinated during storage in the climate chamber.

Table S6. ANOVA table (GLLM) showing the effects of time between monitoring counts, time of count, the wheat line (genotype) and fertilizer on seedling mortality rates of 15 wheat lines in the field from autumn 2008 - spring 2009.

Figure S4. Photograph of GM wheat persisting in the field in winter 2008.

Table S7. Weed species occurring in the plots previously sown with wheat at two vegetation surveys in November 2008 and in April 2009. Nomenclature follows (Lauber and Wagner, 1996Lauber and Wagner, 1996).

Tables S8-S10. ANOVA tables showing effects of wheat line and fertilizer applied during the preceding field season on species richness, Shannon-Weiner diversity index and canopy cover of the post-harvest weed communities. 


\section{References}

Altpeter, F., Diaz, I., McAuslane, H., Gaddour, K., Carbonero, P., Vasil, I.K., 1999. Increased insect resistance in transgenic wheat stably expressing trypsin inhibitor CMe. Molecular Breeding 5, 53-63.

Alvarez-Alfageme, F., von Burg, S., Romeis, J., 2011. Infestation of transgenic powdery mildew-resistant wheat by naturally occurring insect herbivores under different environmental conditions. PLoS One 6(7): e22690. doi:10.1371/journal.pone.0022690

Andersen, N.S., Rasmussen, J., Joergensen, R.B., 2010. You reap what you sow - or do you? Volunteers in organic row-sown and broadcast-sown oilseed rape fields. European Journal of Agronomy 32, 121-126. doi:10.1016/j.eja.2009.09.001

Anderson, R.L., Soper, G., 2003. Review of volunteer wheat (Triticum aestivum) seedling emergence and seed longevity in soil. Weed Technology 17, 620-626.

Andow, D.A., Zwahlen, C., 2006. Assessing environmental risks of transgenic plants. Ecology Letters 9, 196-214.

Bahieldin, A., Mahfouz, H.T., Eissa, H.F., Saleh, O.M., Ramadan, A.M., Ahmed, I.A., Dyer, W.E., El-Itriby, H.A., Madkour, M.A., 2005. Field evaluation of transgenic wheat plants stably expressing the HVA1 gene for drought tolerance. Physiologia Plantarum 123, 421-427.

Bieri, S.J., 1999. Genetic engineering of wheat for increased resistance to fungal pathogens. Diss. Naturwissenschaften ETH Zürich, Nr. 13492. http://dx.doi.org/10.3929/ethz-a003906859. Accessed: 27.06.2015.

Bieri, S., Potrykus, I., Futterer, J., 2003. Effects of combined expression of antifungal barley seed proteins in transgenic wheat on powdery mildew infection. Molecular Breeding 11, 3748.

Braun-Blanquet, J., 1932. Plant Sociology. McGraw-Hill, New York.

Brunner, S., Hurni, S., Herren, G., Kalinina, O., von Burg, S., Zeller, S., Schmid, B., Winzeler, M., Keller, B., 2011. Transgenic Pm3b wheat lines show resistance to powdery mildew in the field. Plant Biotechnol J. 9(8),897-910. doi:10.1111/j.1467-7652.2011.00603.xCasper, B.B., Jackson, R.B., 1997. Plant Competition Underground. Annual Review of Ecology and Systematics 28, 545-570.

Claessen, D., Gilligan, C.A., Lutman, P.J.W., van den Bosch, F., 2005. Which traits promote persistence of feral GM crops? Part 1: Implications of environmental stochasticity. Oikos 110, 20-29.Christensen, A.H, Quail, P.H., 1996. Ubiquitin promoter-based vectors for high-level expression of selectable and/or screenable marker genes in monocotyledonous plants. Transgenic Research 5, 213-218.

Culpepper, A.S., 2006. Glyphosate-induced weed shifts. Weed Technology 20, 277-281.

D'Hertefeldt, T., Jorgensen, R.B., Pettersson, L.B., 2008. Long-term persistence of GM oilseed rape in the seedbank. Biology Letters 4, 314-317.

Dale, P.J., Clarke, B., Fontes, E.M.G., 2002. Potential for the environmental impact of transgenic crops. Nature Biotechnology 20, 567-574.

De Corby, K.A., Van Acker, R.C., Brûlé-Babel, A.L., Friesen, L.F., 2007. Emergence timing and recruitment of volunteer spring wheat. Weed Science 55, 60-69.

Demeke, T., Perry, D.J., Scowcroft, W.R., 2006. Adventitious presence of GMOs: Scientific overview for Canadian grains. Canadian Journal of Plant Science 86, 1-23.

DeWitt, T.J., Sih, A., Wilson, D.S., 1998. Costs and limits of phenotypic plasticity. Trends in Ecology \& Evolution 13, 77-81. 
Duc, C., Nentwig, W., Lindfeld, A., 2011. No adverse effect of genetically modified antifungal wheat on decomposition dynamics and the soil fauna community - a field study. PLoS ONE 6, e25014. doi:10.1371/journal.pone.0025014

EC, 2001. Directive 2001/18/EC of 12 March 2001 on the deliberate release into the environment of genetically modified organisms and repealing Council Directive 90/220/EC, 17.4.2001. Official Journal of the European Communities L 106/1-38.

EFSA, 2011. Guidance for risk assessment of food and feed from genetically modified plants, EFSA Journal 9, 2150.

Elisseou, G.C., Veresoglou, D.S., Mamolos, A.P., 1995. Vegetation productivity and diversity of acid grasslands in Northern Greece as influenced by winter rainfall and limiting nutrients. Acta Oecologica-International Journal of Ecology 16, 687-702.

Ellstrand, N.C., 2003a. Dangerous liaisons? When cultivated plants mate with their wild relatives. John Hopkins University press, p. 81-83.

Ellstrand, N.C., 2003b. Current knowledge of gene flow in plants: implications for transgene flow. Philosophical Transactions of the Royal Society B-Biological Sciences 358(1434), 1163-1170. doi:10.1098/rstb.2003.1299

Eyal, Z., Scharen, A.L., Prescott, J.M., van Ginkel, M., 1987. The septoria diseases of wheat: Concepts and methods of disease management. D.F. Mexico: International Maize and Wheat Improvement Center. $46 \mathrm{p}$.

FAO, 2015. Global cereal supply and demand brief. Prospects for world cereal production in 2015 improve. Food and Agriculture Organization of the United Nations. Available: http://www.fao.org/worldfoodsituation/csdb/en/. Accessed: 07 June 2015.

Finckh, Gacek, Czembor, Wolfe, 1999. Host frequency and density effects on powdery mildew and yield in mixtures of barley cultivars. Plant Pathology 48, 807-816. doi: 10.1046/j.13653059.1999.00398.x

Foster, B.L., Gross, K.L., 1998. Species richness in a successional grassland: effects of nitrogen enrichment and plant litter. Ecology 79, 2593-2602.

Friesen, L.F., Nelson, A.G., Van Acker, R.C., 2003. Evidence of contamination of pedigreed canola (Brassica napus) seedlots in western Canada with genetically engineered herbicide resistance traits. Agronomy Journal 95, 1342-1347.

Gilbert, M., 2013. Superweeds? Suicides? Stealthy genes? The true, the false and the still unknown about transgenic crops. Nature 497, 24-26.

Grace, J. Perspectives on Plant Competition, 2012. Elsevier - 498 p.

Green, G.M., Owen, M.D.K., 2011. Herbicide-resistant crops: Utilities and limitations for herbicide-resistant weed management. Journal of Agricultural and Food Chemistry 59 (11), 5819-5829. doi: 10.1021/jf101286h

Gruber, S., Pekrun, C., Claupein, W., 2004. Seed persistence of oilseed rape (Brassica napus): variation in transgenic and conventionally bred cultivars. The Journal of Agricultural Science 142, 29-40.

Guadagnuolo, R., Savova-Bianchi, D., Felber, F., 2001. Gene flow from wheat (Triticum aestivum L.) to jointed goatgrass (Aegilops cylindrica Host.), as revealed by RAPD and microsatellite markers. Theoretical and Applied Genetics 103(1), 1-8. doi:10.1007/s001220100636

Gyamfi, S., Pfeifer, U., Stierschneider, M., Sessitsch, A., 2002. Effects of transgenic glufosinatetolerant oilseed rape (Brassica napus) and the associated herbicide application on eubacterial 
and Pseudomonas communities in the rhizosphere. FEMS Microbiology Ecology 41, 181190.

Hails, R.S., 2000. Genetically modified plants - the debate continues. Trends in Ecology \& Evolution 15, 14-18.

Hails, R.S., Rees, M., Kohn, D.D., Crawley, M.J., 1997. Burial and seed survival in Brassica napus subsp. oleifera and Sinapis arvensis including a comparison of transgenic and nontransgenic lines of the crop. Proceedings of the Royal Society of London. Series B: Biological Sciences 264, 1-7.

Hancock, J.F., 2003. A framework for assessing the risk of transgenic crops. BioScience 53, $512-519$.

Harker, K.N., Clayton, G.W., Blackshaw, R.E., O'Donovan, J.T., Johnson, E.N., Gan, Y., Holm, F.A., Sapsford, K.L., Irvine, R.B., Van Acker, R.C., 2005a. Glyphosate-resistant wheat persistence in western Canadian cropping systems. Weed Science 53, 846-859.

Harker, K.N., Clayton, G.W., Blackshaw, R.E., O'Donovan, J.T., Lupwayi, N.Z., Johnson, E.N., Gan, Y., Zentner, R.P., Lafond, G.P., Irvine, R.B., 2005b. Glyphosate-resistant spring wheat production system effects on weed communities. Weed Science 53, 451-464.

Hilbeck, A., 2001. Implications of transgenic, insecticidal plants for insect and plant biodiversity. Perspectives in Plant Ecology, Evolution and Systematics 4, 43-61.

Holman, J.D., Schlegel, A.J., Olson, B.L., Maxwell, S.R., 2011. Volunteer glyphosate-tolerant corn reduces soil water and winter wheat yields. Crop Management 10 (1). doi:10.1094/CM2011-0629-01-RS

Joergensen, R.B., Hauser, T., D'Hertefeldt, T., Andersen, N.S., Hooftman, D., 2009. The variability of processes involved in transgene dispersal-case studies from Brassica and related genera. Environmental Science and Pollution Research 16, 389-395. doi: 10.1007/s11356009-0142-4

Kalinina, O., Zeller, S.L., Schmid, B., 2011. Competitive performance of transgenic wheat resistant to powdery mildew. PLoS ONE 6 (11), e28091. doi:10.1371/journal.pone.0028091

Knispel, A.L., McLachlan, S.M., 2010. Landscape-scale distribution and persistence of genetically modified oilseed rape (Brassica napus) in Manitoba, Canada. Environmental Science and Pollution Research 17, 13-25.

Lauber, K., Wagner, G., 1996. Flora Helvetica. Flora der Schweiz. Verlag Paul Haupt Bern, Stuttgart, Wien.

Leah, R., Tommerup, H., Svendsen, I., Mundy, J., 1991. Biochemical and molecular characterization of three barley seed proteins with antifungal properties. Journal of Biological Chemistry 266, 1564-1573.

Linder, C.R., Schmitt, J., 1994. Assessing the risks of transgene escape through time and cropwild hybrid persistence. Molecular Ecology 3, 23-30.

Lutman, P.J.W., Berry, K., Payne, R.W., Simpson, E., Sweet, J.B., Champion, G.T., May, M.J., Wightman, P., Walker, K., Lainsbury, M., 2005. Persistence of seeds from crops of conventional and herbicide tolerant oilseed rape (Brassica napus). Proceedings of the Royal Society B: Biological Sciences 272, 1909-1915.

Mallory-Smith, C., Zapiola, M., 2008. Gene flow from glyphosate-resistant crops. Pest Management Science 64, 428-440.

McCullagh, P., Nelder, J.A., 1989. Generalized linear models. Chapman and Hall, London. 
Menegus, F., Cattaruzza, L., Mattana, M., Beffagna, N., Ragg, E., 1991. Response to anoxia in rice and wheat seedlings: Changes in the $\mathrm{pH}$ of intracellular compartments, glucose-6phosphate level, and metabolic rate. Plant Physiology, 760-767.

Mercer, K.L., Wainwright, J.D., 2008. Gene flow from transgenic maize to landraces in Mexico: An analysis. Agriculture, Ecosystems \& Environment 123, 109-115.

Meyer, J.B., Song-Wilson, Y., Foetzki, A., Luginbühl, C., Winzeler, M., Kneubühler, Y., Matasci, C., Mascher-Frutschi, F., Kalinina, O., Boller, T., Keel, C., Maurhofer, M., 2013. Does wheat genetically modified for disease resistance affect root-colonizing pseudomonads and arbuscular mycorrhizal fungi? PLoS ONE 8, e53825.

Morinaga, T., 1926. Germination of seeds under water. American Journal of Botany 13, 126140.

Mortensen, D.A., Egan J.F., Maxwell, B.D., Ryan, M.R., Richard G. Smith R.G., 2012. Navigating a Critical Juncture for Sustainable Weed Management. BioScience 62 (1), 75-84. doi: 10.1525/bio.2012.62.1.12

Mountford, J.O., Lakhani, K.H., Kirkham, F.W., 1993. Experimental assessment of the effects of nitrogen addition under hay-cutting and aftermath grazing on the vegetation of meadows on a somerset peat moor. Journal of Applied Ecology 30, 321-332.

Mundt, C.C., 2002. Use of multiline cultivars and cultivar mixtures for disease management. Annu Rev Phytopathol 40, 381-410.

Nielson, R.L., McPherson, M.A., O'Donovan, J.T., Harker, K.N., Yang, R.-C., Hall, L.M., 2009. Seed-mediated gene flow in wheat: seed bank longevity in Western Canada. Weed Science 57, 124-132.

Pajkovic, M., Lappe, S., Barman, R., Parisod, C., Neuenschwander, S., Goudet, J., Alvarez, N., Guadagnuolo, R., Felber, F. and Arrigo, N., 2014. Wheat alleles introgress into selfing wild relatives: empirical estimates from approximate Bayesian computation in Aegilops triuncialis. Molecular Ecology, 23: 5089-5101. doi: 10.1111/mec.12918

Pellegrineschi, A., Noguera, L.M., Skovmand, B., Brito, R.M., Velazquez, L., Salgado, M.M., Hernandez, R., Warburton, M., Hoisington, D., 2002. Identification of highly transformable wheat genotypes for mass production of fertile transgenic plants. Genome 45, 421-430.

Perata, P., Pozueta-Romero, J., Akazawa, T., Yamaguchi, J., 1992. Effect of anoxia on starch breakdown in rice and wheat seeds. Planta 188, 611-618.

Peter, M., Lindfeld, A., Nentwig, W., 2010. Does GM wheat affect saprophagous Diptera species (Drosophilidae, Phoridae)? Pedobiologia 53, 271-279.

Piñeyro-Nelson, A., Van Heerwaarden, J., Perales, H. R., Serratos-Hernández, J. A., Rangel, A., Hufford, M.B., Gepts, P., Garay-Arroyo, A., Rivera-Bustamante, R., Álvarez-Buylla, E.R., 2009. Transgenes in Mexican maize: molecular evidence and methodological considerations for GMO detection in landrace populations. Molecular Ecology 18, 750-761. doi: 10.1111/j.1365-294X.2008.03993.x

Reed, J., Privalle, L., Powell, M.L., Meghji, M., Dawson J., Meghji, M., Dawson, J., Dunder, E., Sutthe, J., Wenck, A., Launis, K., Kramer, C., Chang, Y.-F., Hansen, G., Wright, M., 2001. Phosphomannose isomerase: An efficient selectable marker for plant transformation, In Vitro Cellular and Developmental Biology Plant 37, 127-132.

Rottstock, T., Joshi, J., Kummer, V., Fischer, M., 2014. Higher plant diversity promotes higher diversity of fungal pathogens, while it decreases pathogen infection per plant. Ecology 95, 1907-1917. http://dx.doi.org/10.1890/13-2317.1 
Purrington, C.B., Bergelson, J., 1995. Assessing weediness of transgenic crops - Industry plays plant ecologist. Trends in Ecology \& Evolution 10, 340-342.

Quist, D., Chapela I.H., 2001. Transgenic DNA introgressed into traditional maize landraces in Oaxaca, Mexico. Nature 414, 541-543.

Schafer, M.G., Ross, A.A., Londo, J.P., Burdick, C.A., Lee, E.H., Travers, S.E., Van de Water, P.K., Sagers, C.L., 2011. The establishment of genetically engineered canola populations in the U.S. PLoS ONE 6(10), e25736. doi:10.1371/journal.pone.0025736

Schmitt, J., Linder, C.R., 1994. Will escaped transgenes lead to ecological release. Molecular Ecology 3, 71-74.

Sivamani, E., Bahieldin, A., Wraith, J.M., Al-Niemi, T., Dyer, W.E., Ho, T.H.D., Qu, R.D., 2000a. Improved biomass productivity and water use efficiency under water deficit conditions in transgenic wheat constitutively expressing the barley HVA1 gene. Plant Science 155, 1-9.

Sivamani, E., Brey, C.W., Dyer, W.E., Talbert, L.E., Qu, R.D., 2000b. Resistance to wheat streak mosaic virus in transgenic wheat expressing the viral replicase (NIb) gene. Molecular Breeding 6, 469-477.

Snow, A.A., 2002. Transgenic crops - why gene flow matters. Nature Biotechnology 20, $542-$ 542.

Snow, A.A., Pilson, D., Rieseberg, L.H., Paulsen, M.J., Pleskac, N., Reagon, M.R., Wolf, D.E., Selbo, S.M., 2003. A Bt transgene reduces herbivory and enhances fecundity in wild sunflowers. Ecological Applications 13, 279-286.

Song Wilson, Y., Wiemken, A., Boller, T., 2010. Interplay of arbuscular mycorrhizal fungi with transgenic and nontransgenic wheat. IOBC/wprs Bulletin 62, 91-95.

Stoger, E., Williams, S., Christou, P., Down, R.E., Gatehouse, J.A., 1999. Expression of the insecticidal lectin from snowdrop (Galanthus nivalis agglutinin; GNA) in transgenic wheat plants: effects on predation by the grain aphid Sitobion avenae. Molecular Breeding 5, 65-73.

Sun, A.-Q., Zhang, C.-Q., Wu, C.-L., Gao, Q.-R., 2015. Pollen flow of wheat under natural conditions in the Huanghuai River Wheat Region, China. GM Crops \& Food: Biotechnology in Agriculture and the Food Chain, 2164-5698. doi:10.1080/21645698.2015.1006072

Tollrian, R., Harvell, C.D., 1999. The evolution of inducible defences: current ideas., in: Tollrian R, H.C. (Ed.), The Ecology and Evolution of Inducible Defence. Princeton University Press, pp. 306-321.

Trenbath BR, 1977. Interactions among diverse hosts and diverse parasites. Annals of the New York Academy of Sciences 287, 124-150.

Van Dam, N.M., Baldwin, I.T., 2001. Competition mediates costs of jasmonate-induced defences, nitrogen acquisition and transgenerational plasticity in Nicotiana attenuata. Functional Ecology 15, 406-415.

Van der Maarel, E., 2007. Transformation of cover-abundance values for appropriate numerical treatment - Alternatives to the proposals by Podani. Journal of Vegetation Science 18, 767770.

Vasil, I.K., Bean, S., Zhao, J.M., McCluskey, P., Lookhart, G., Zhao, H.P., Altpeter, F., Vasil, V., 2001. Evaluation of baking properties and gluten protein composition of field grown transgenic wheat lines expressing high molecular weight glutenin gene 1Ax1. Journal of Plant Physiology 158, 521-528.

Von Burg, S., Muller, C.B., Romeis, J., 2010. Transgenic disease-resistant wheat does not affect the clonal performance of the aphid Metopolophium dirhodum Walker. Basic Appl. Ecol. 11, 257-263. 
Waines, J.G., Hegde, S.G., 2003. Intraspecific gene flow in bred wheat as affected by reproductive biology and pollination ecology of wheat flowers. Crop Science 42(2), 451-463. doi:10.2135/cropsci2003.4510

Wang, W., Xia, H.,Yang, X., Xu, T., Si, H. J., Cai, X.X., Wang, F., Su, J., Snow, A.A., Lu, B.R., 2014a. A novel 5-enolpyruvoylshikimate-3-phosphate (EPSP) synthase transgene for glyphosate resistance stimulates growth and fecundity in weedy rice (Oryza sativa) without herbicide. New Phytologist 202, 1469-8137. doi:10.1111/nph.12428

Wang, Y., Cheng, X., Shan, Q., Zhang, Y., Liu, J., Gao, C., Qiu, J.-L., 2014b. Simultaneous editing of three homoeoalleles in hexaploid bread wheat confers heritable resistance to powdery mildew. Nature Biotechnology 32, 947-951. doi:10.1038/nbt.2969

Warwick, S.I., Beckie, H.J., Hall, L.M., 2009. Gene flow, invasiveness, and ecological impact of genetically modified crops. Annals of the New York Academy of Sciences 1168, 72-99.

Willems, J.H., Peet, R.K., Bik, L., 1993. Changes in chalk-grassland structure and species richness resulting from selective nutrient additions. Journal of Vegetation Science 4, 203-212.

Wolfe, M.S., 2000. Crop strength through diversity. Nature 406, 681-682.

Vencill, W.K., Nichols R.L, Webster, T.M., Soteres, J.K., Mallory-Smith, C., Burgos, N.R., Johnson, W.G., McClelland, M.R., 2012. Herbicide Resistance: Toward an understanding of resistance development and the impact of herbicide-resistant crops. Weed Science: Special Issue 2012 60, 2-30.

Xue, Z.-Y., Zhi, D.-Y., Xue, G.-P., Zhang, H., Zhao, Y.-X., Xia, G.-M., 2004. Enhanced salt tolerance of transgenic wheat (Triticum aestivum $\mathrm{L}$.) expressing a vacuolar $\mathrm{Na}+\mathrm{H}+$ antiporter gene with improved grain yields in saline soils in the field and a reduced level of leaf $\mathrm{Na}+$ Plant Science 167, 849-859.

Yahiaoui, N., Srichumpa, P., Dudler, R., Keller, B., 2004. Genome analysis at different ploidy levels allows cloning of the powdery mildew resistance gene Pm3b from hexaploid wheat. Plant Journal 37, 528-538.

Zadoks, J.C., Chang, T.T., Konzak, C.F., 1974. Decimal code for growth stages of cereals. Weed Research 14, 415-421.

Zeller, S., Kalinina, O., Brunner, S., Keller, B., Schmid, B., 2010. Transgene $\times$ environment interactions in genetically modified wheat. PLoS ONE 5, e11405. doi:10.1371/journal.pone.0011405

Zeller, S.L., Kalinina, O., Flynn, D.F., Schmid, B., 2012. Mixtures of genetically modified wheat lines outperform monocultures. Ecol Appl. 22(6), 1817-26.

Zeller, S.L., Kalinina, O., Schmid, B., 2013. Costs of resistance to fungal pathogens in genetically modified wheat. J Plant Ecol 6(1): 92-100. doi:10.1093/jpe/rts013

Zhu, Y., Chen, H., Fan, J., Wang, Y., Li, Y., Chen, J., Fan, J., Yang, S., Hu, L., Leung, H., Mew, T.W., Teng, P.,S., Wang, Z., Mundt, C.C., 2000. Genetic diversity and disease control in rice. Nature 406, 718-722. doi:10.1038/35021046.

Zhu, Q., Maher, E.A., Masoud, S., Dixon, R.A., Lamb, C.J., 1994. Enhanced protection against fungal attack by constitutive coexpression of chitinase and glucanase genes in transgenic tobacco. Nature Biotechnology 12, 807-812. 


\section{Figure legends}

Figure 1. Mildew incidence and performance of wheat lines grown without competition or in weed communities. Left column - mildew incidence and performance of the 15 wheat lines grown without competition. Right column — mildew incidence and performance of the 15 wheat lines in the weed communities. The data for high and low nutrient treatments and for two different weed communities are pooled as these treatments did not significantly affect the differences in performance between GM and non-GM wheat lines. Bars represent means \pm standard errors. Four grades of the grey scale indicate groups of wheat lines: dark-grey transgenic lines, grey - the genetically closest control (sister lines), light-grey - wheat varieties used for transgene insertion, white - modern conventional wheat varieties.

Figure 2. Mortality rates of seedlings of the GM and non-GM wheat lines. Left upper chart — no nutrient addition during vegetation season 2008. Right upper chart — nutrient addition. Mortality rates in $\%$, i.e. the percentage of dead seedlings out of total seedlings alive at previous count, are shown. Bobwhite GM and non-GM lines are shown in black, Frisal GM and non-GM lines are shown in grey. Left lower chart — weather conditions from November 2008 until April 2009: average air and soil temperature measured in ${ }^{0} \mathrm{C}$ (left axis) and precipitation measure in $\mathrm{mm}$ (right axis). The meteorological data were provided by the Federal Office of Meteorology and Climatology of Switzerland.

Figure 3. PCO ordinations for the abundance and occurrence of the weed species in wheat fallow plots. Column A - Euclidean distances matrix for the abundance of the weed species in GM and non-GM wheat follow plots. Column B - Jaccard similarity matrix for the occurrence of the weed species in GM and non-GM wheat follow plots. The axes are the first and the second ordination axes for principal coordinates analysis. The results of the two vegetation counts in autumn 2008 and in spring 2009 are presented. Open symbols indicate the plots which received no fertilizer, closed symbols those which were fertilized twice in the preceding field season 2008. 


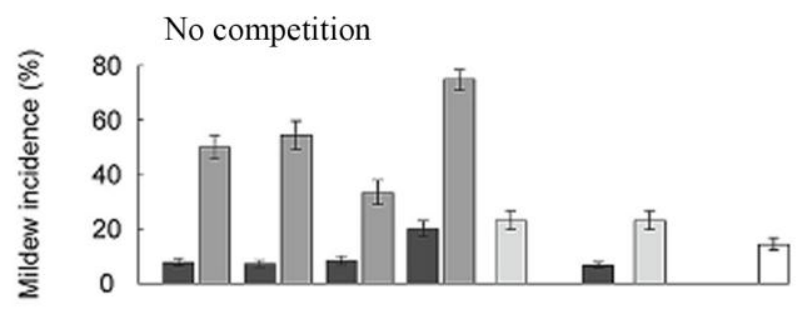

Competition with weeds
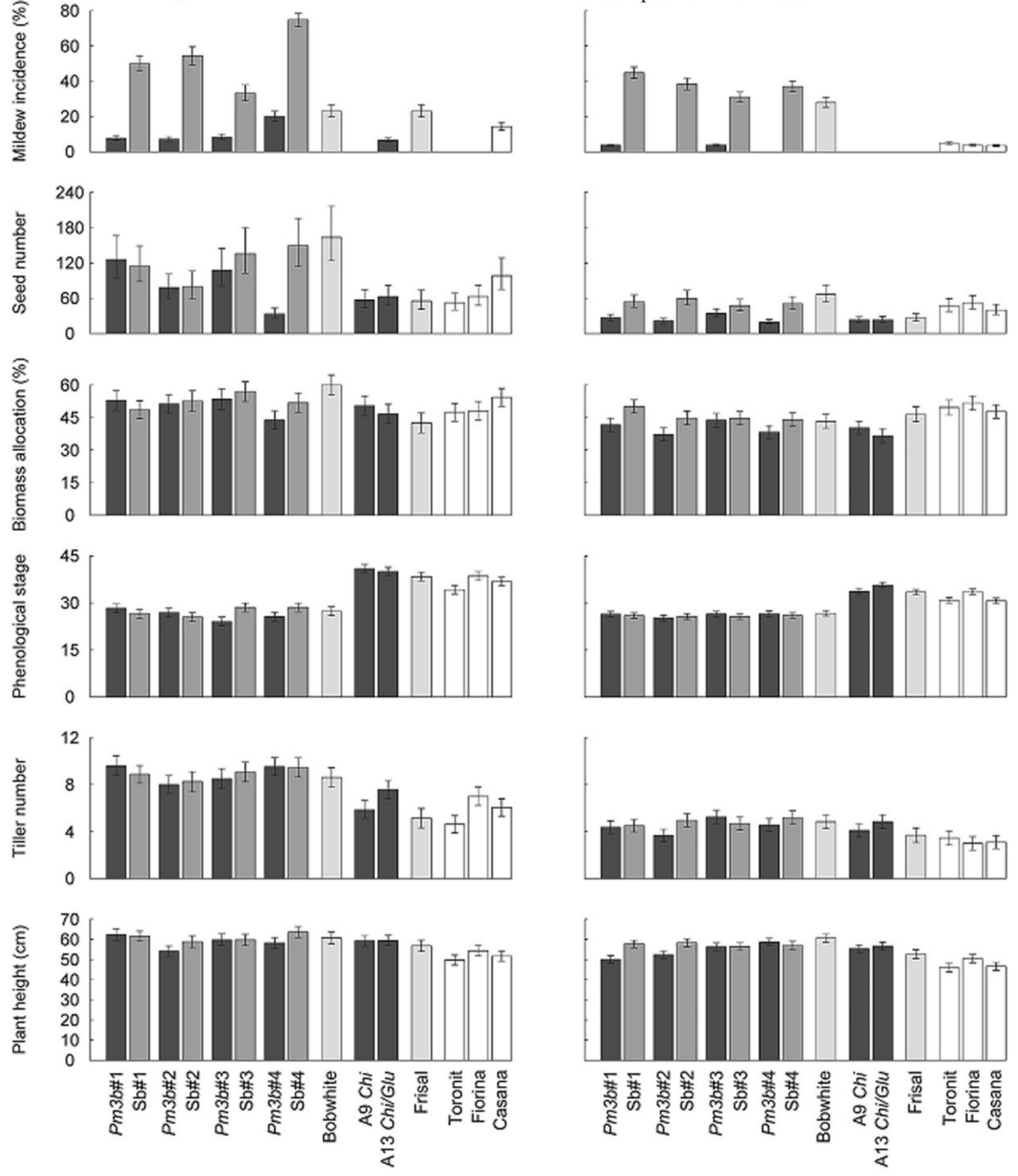

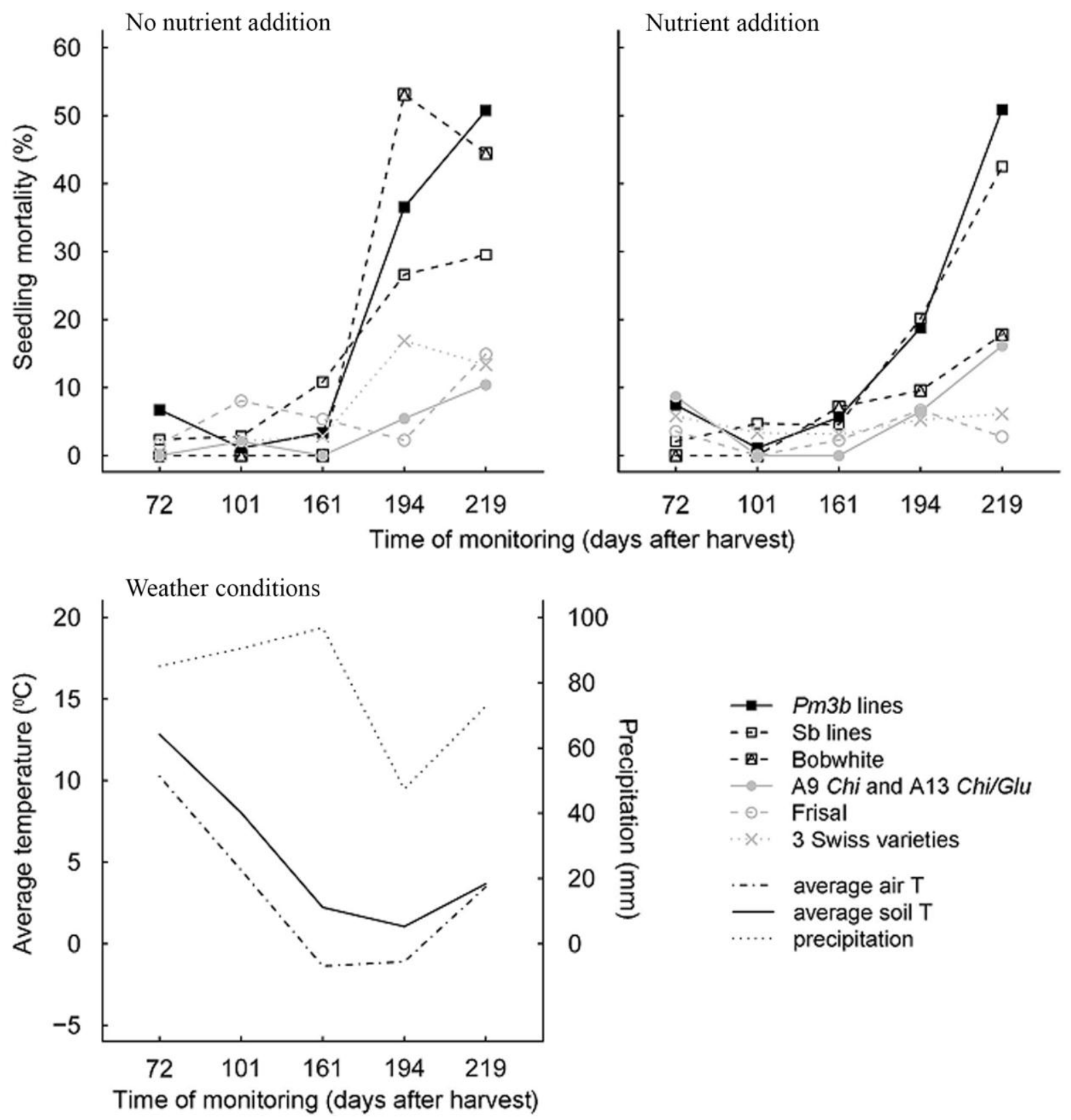
A

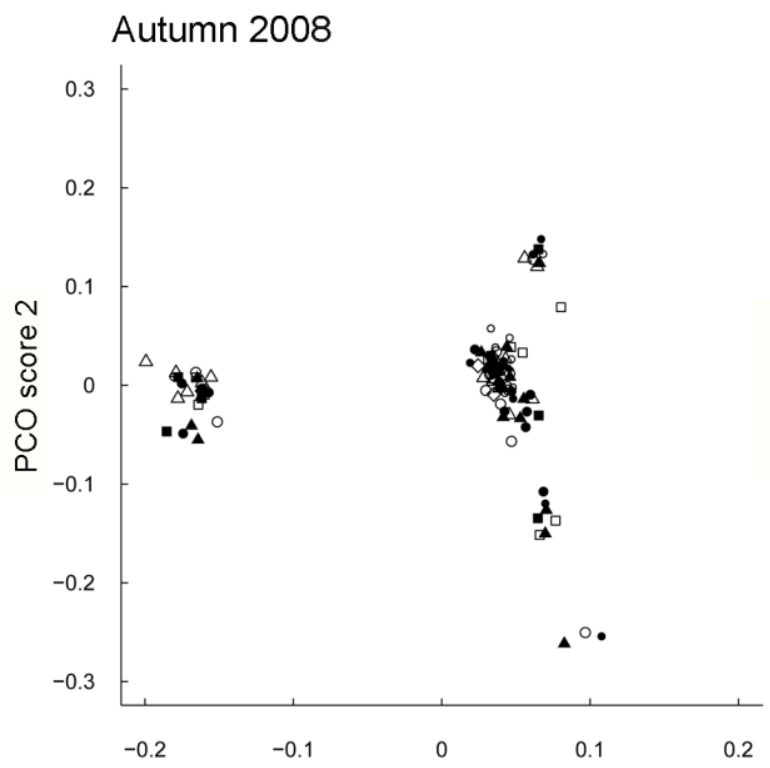

Spring 2009

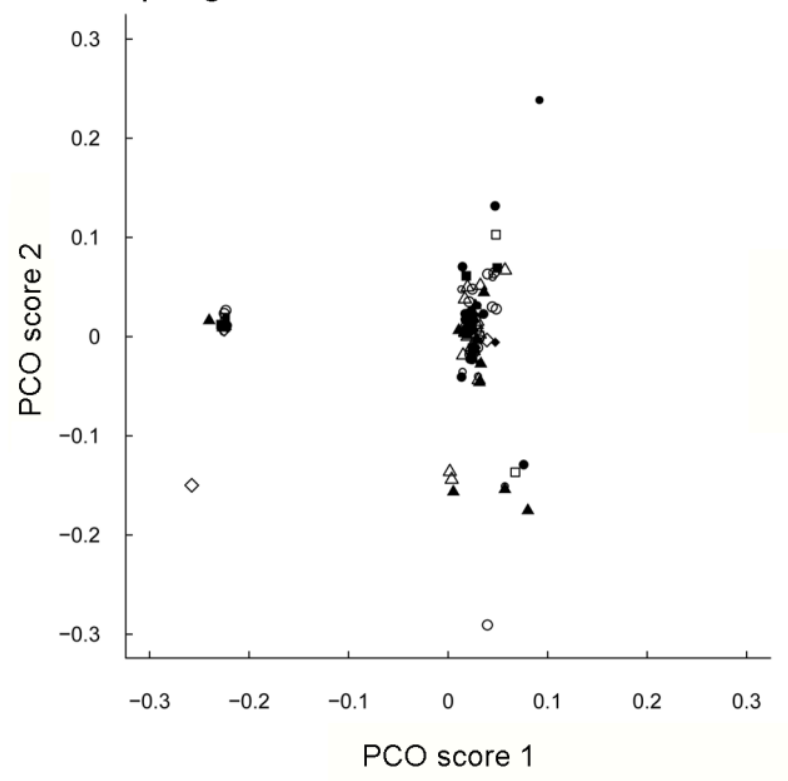

B
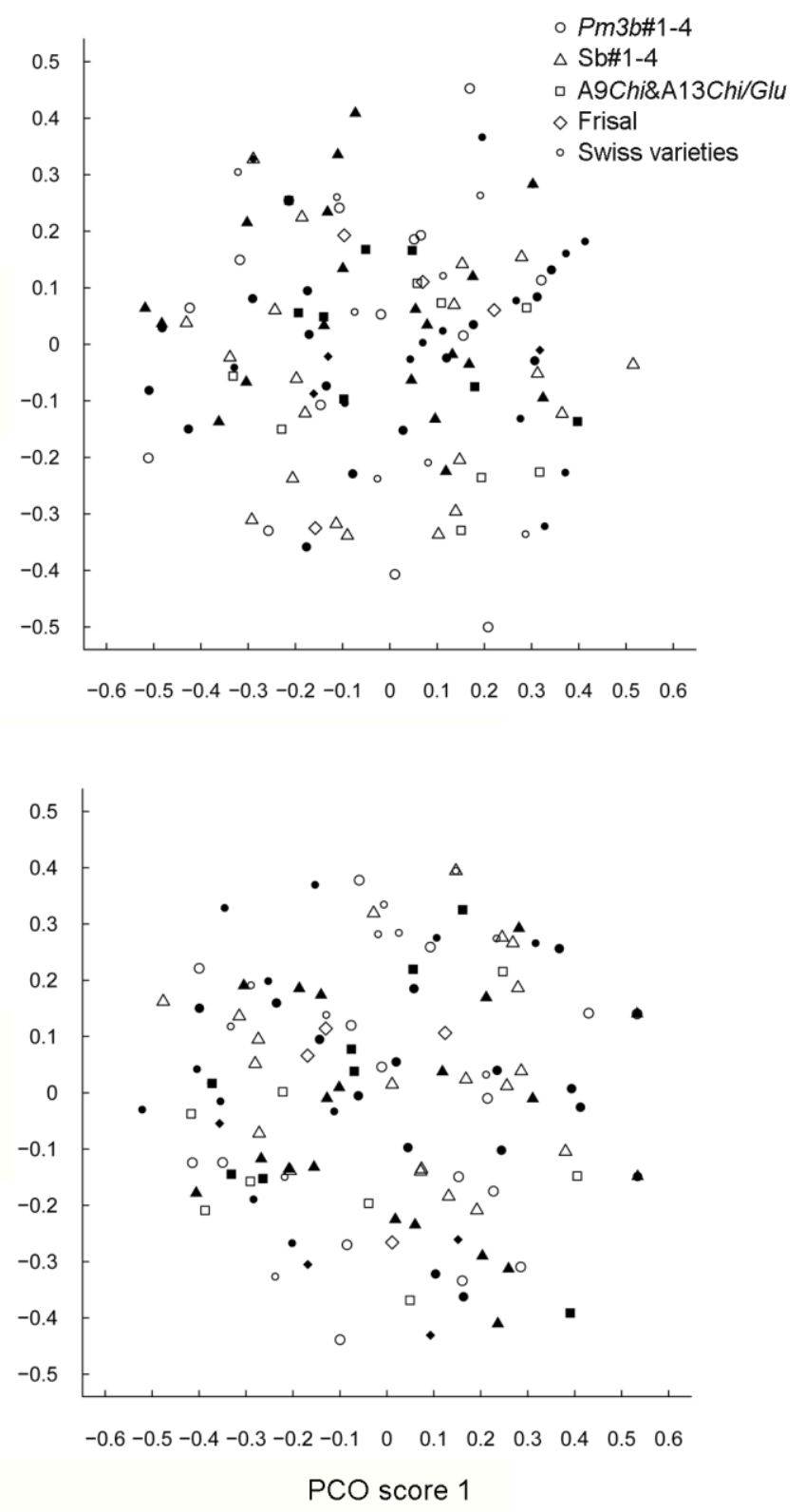